MATEC Web of Conferences 9, 02001 (2013)

DOI: $10.1051 /$ matecconf/20130902001

(C) Owned by the authors, published by EDP Sciences, 2013

\title{
Fire resistance without fire resistant glazing
}

\author{
Johan Koudijs B.Sc and Csilla Csoke M.Eng
}

\author{
DGMR Bouw B.V., Arnhem, The Netherlands
}

\begin{abstract}
Fire resistant glazing is a high tech product but it has its price. In some cases, for instance for buildings near transport routes of petrochemical products, large areas of façade have to be able to withstand heat from large pool fires in order to allow for the safe evacuation of these buildings. This paper explains the thermal loads on fire resistant glazing when tested according to European standards and compares these loads to the situation of a facade exposed to a pool fire. It shows an example of building developments close to rail and waterways with hazardous goods transports that led to research on a low budget solution to fireproof facades without using fire resistant glazing and will also show the results of this research.
\end{abstract}

\section{INTRODUCTION}

In a densely populated country like The Netherlands, the transportation of dangerous goods over roads, railways, and by container ships is a serious threat to Dutch citizens. Transportation is only allowed on designated routes, as assigned by the government. This does not mean that all risk is eliminated.

In the legislation in The Netherlands, Quantitative Risk Analysis (QRA) is compulsory in Environmental Planning. In this analysis, the risk of dying of one individual or a group of individuals is determined. Mitigating measures must be taken if the risk exceeds certain values.

Keeping a safe distance between the transportation route and building development is a simple solution, but not always practical and, as the following case shows, not always necessary since alternative solutions can be devised.

\section{CASE STUDY: THE ROTTERDAM TOWER}

\section{Project description}

There is a new development of several high-rise buildings (140-160 m) on the waterfront of the river 'New Maas'. It is located on a peninsula in the centre of Rotterdam, along the quay that used to be the 'home' of the Holland-America line. The river is a busy axis for the transportation of large quantities of goods from the port of Rotterdam to the German industry in the Ruhr area.

According to an Environmental Planning rule [1], the distance from the edge of the water to the nearest building must be at least $25 \mathrm{~m}$. Furthermore, in all buildings between 25 and $40 \mathrm{~m}$ from the quay, measures have to be taken to ensure that the occupants of the buildings have sufficient time to evacuate in case of en emergency on the river. Only buildings at a distance of at least $40 \mathrm{~m}$ are considered sufficiently safe without taking measures against incidents on the river.

The peninsula (called 'Kop van Zuid'), on which the high-rise tower 'The Rotterdam' will also arise, is only $175 \mathrm{~m}$ wide. Developing buildings $40 \mathrm{~m}$ from the quay means a huge waste of potential area for building development. Building closer to the river requires a fully fire resistant façade at each waterfront-facing elevation.

Our company was asked to find a cost effective way to protect 'The Rotterdam' building without fire resistant façade construction, more specifically without fire resistant glazing.

This is an Open Access article distributed under the terms of the Creative Commons Attribution License 2.0, which permits unrestricted use, distribution, and reproduction in any medium, provided the original work is properly cited. 


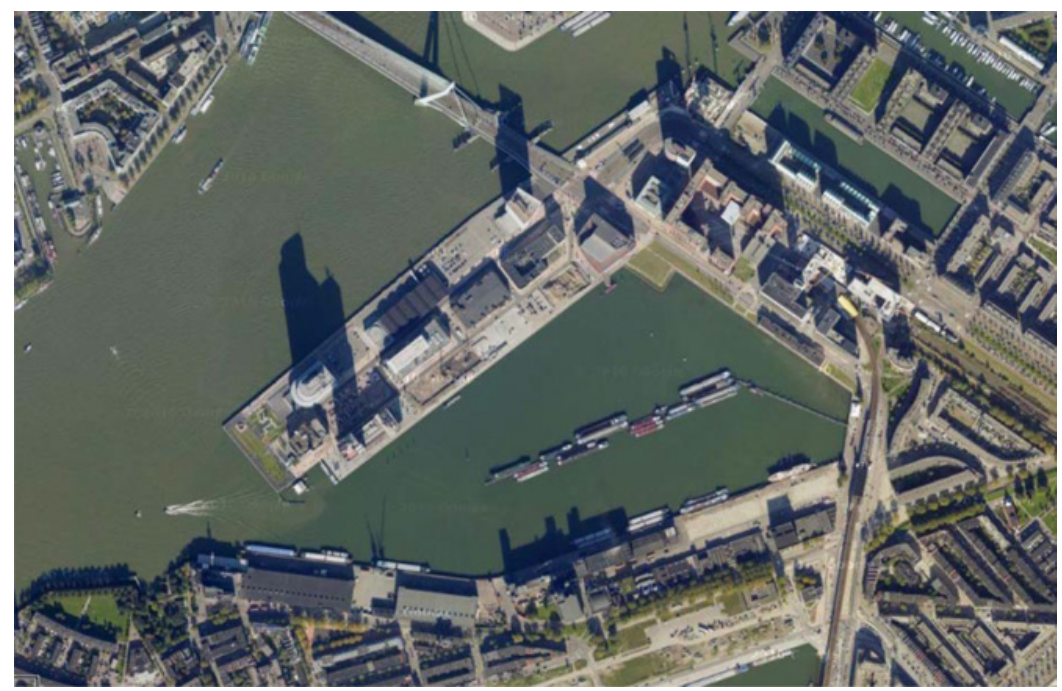

Figure 1. Peninsula "Kop van Zuid", Rotterdam.

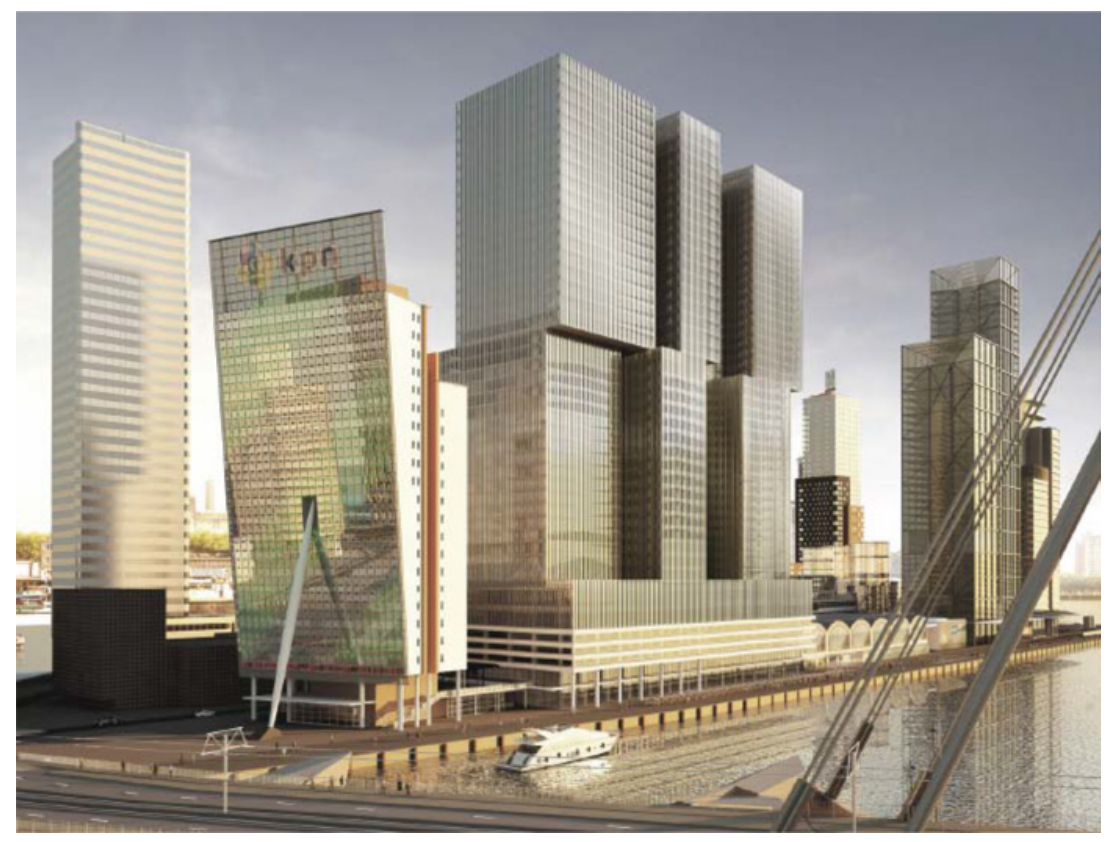

Figure 2. High-Rise Development "The Rotterdam” (impression by OMA).

\section{Scenario}

The incident scenario that local regulations [2] prescribes a collision between two inland vessels spilling 75 tonnes of highly flammable liquid, leading to a pool fire with a diameter of $25 \mathrm{~m}$ and a flame height of almost $40 \mathrm{~m}$. This serious fire can last for 30 minutes given the amount of fuel. The heat radiation flux emitted by the lower part of the flames will be approx. $130 \mathrm{~kW} / \mathrm{m}^{2}$ (compare to the $0.7-0.8 \mathrm{~kW} / \mathrm{m}^{2}$ 


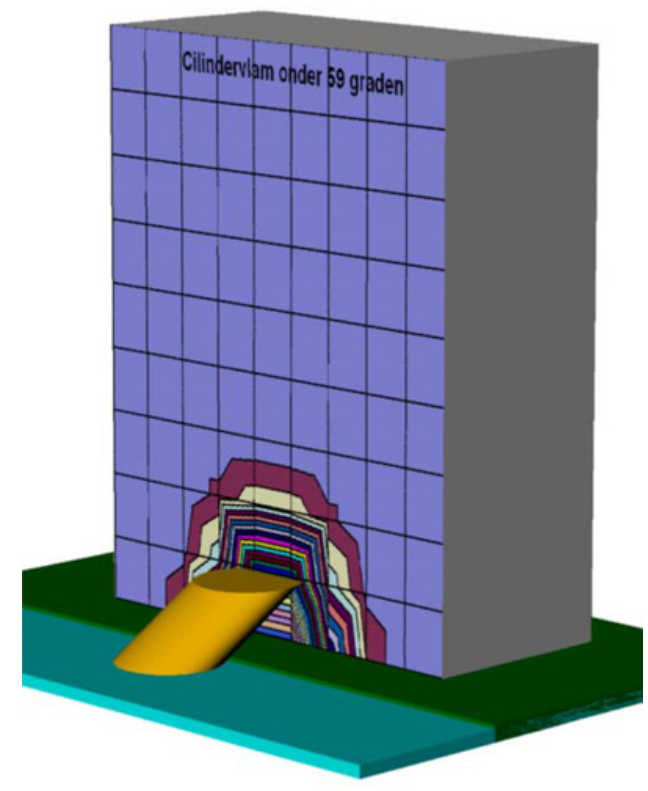

Figure 3. Pool fire exposure of the facade.

solar radiation). At higher levels of the flame the radiation will drop to $50 \mathrm{~kW} / \mathrm{m}^{2}$ or even lower because of obscuration by heavy smoke [2].

In addition to the effects of the high thermal radiation from a vertical flame, the influence of the wind has to be taken into account. According to the research by TNO [3], wind speeds up to $9 \mathrm{~m} / \mathrm{s}$ should be expected that tilt the flames towards the building. If both the building and the burning pool are close to the quay edge, the flames will impinge on a part of the façade of the building. In these parts of the facade, fire resistant glazing will be installed. The other parts of the façade, for instance on ground floor level, will only suffer from the high radiation levels emitted by the fire.

The strength of radiation received by the façade was calculated using WinTherm ${ }^{\circledR}$, ver 8.1.1. This 3-D thermal simulations software calculates thermal radiation exchange between solid surfaces. By modeling the flame from the pool fire as a solid body with a prescribed surface temperature distribution and constant emissivity, the pattern of radiant flux incident on the complex building facade was determined. The calculations show that large areas of the water-facing elevation receive heat flux up to $41 \mathrm{~kW} / \mathrm{m}^{2}$.

An incident radiation level of about $15 \mathrm{~kW} / \mathrm{m}^{2}$ is needed to 'pilot ignite' combustible objects in the presence of a small flame according to the European standard EN 13501-2. Heat fluxes above $30-35 \mathrm{~kW} / \mathrm{m}^{2}$ are required for autoignition, i.e. ignition of the object without the aid of an additional heat source. For sufficient protection of the facade against igniting, all areas receiving a higher flux than $15 \mathrm{~kW} / \mathrm{m}^{2}$, measures should be taken to prevent ignition of fire by so-called auto-ignition: if the heat radiation reaches a certain level, materials can burn without actually coming into contact with the flames.

\section{Target}

As mentioned in the introduction, the traditional solution in these situations is to provide a fire resistant façade construction, including fire resistant glazing. In this case we are confident that even in the worst coincidence (large flame, directly at the quay, adverse wind strength and direction), only a limited fraction of the facade is in actual contact with flames, whereas the major part of the facade is subjected 


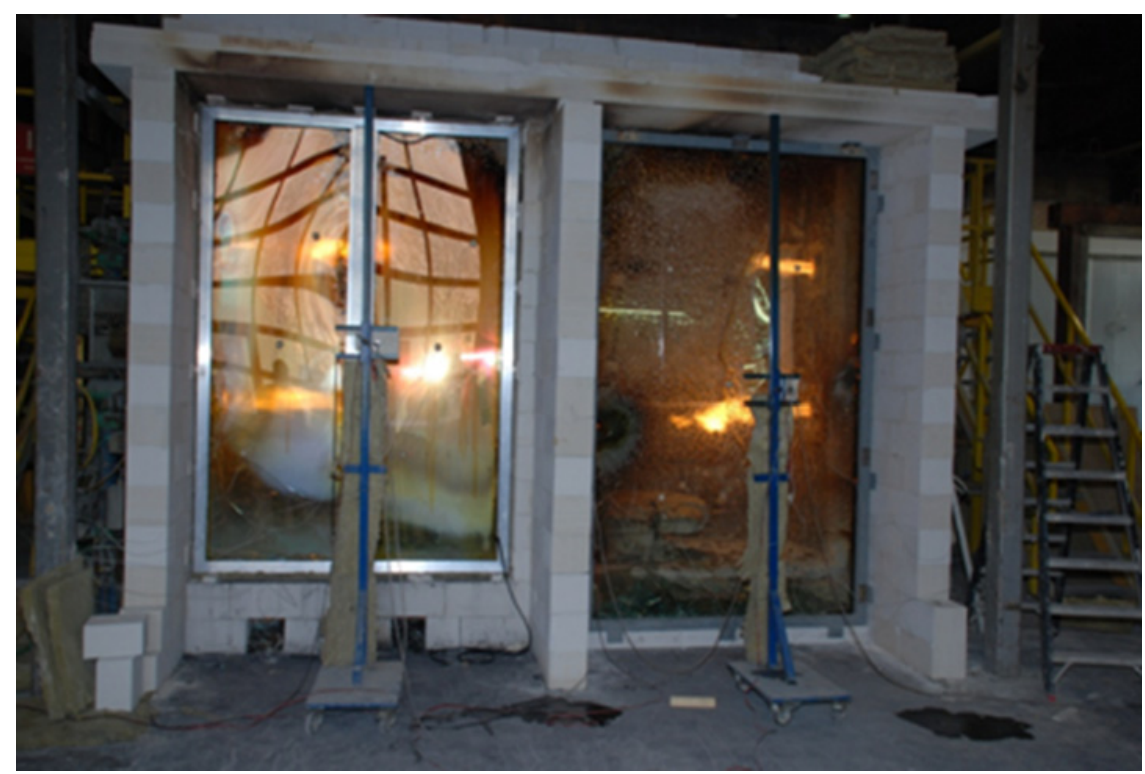

Figure 4. Test specimen in front of furnace in modified setup.

only to predictable levels of heat radiation. The problem is now to translate these specific 'thermal load' conditions to fire resisting properties determined in standardized tests under conventional fire exposure.

We considered that for the 'majority part' of the facade subject to radiation only, it should be sufficient to apply a façade system - and glazing - that offers 30 minutes of fire resistance (Integrity and Radiation) based on the external fire conditions according to EN 1363-2; classified as EW30-ef under EN 13501-2.

There are actually two problems two be solved with this requirement, a theoretical and a practical one: Standard testing according to the external fire conditions means exposure to heat radiation as well as contact with flames and hot gases. In our case, only the heat radiation has to be taken into account. The other problem is that there is no fire resistant glazing with classification EW30-ef available on the market. Glass suppliers only provide glass tested according to the standard fire curve for internal exposure. Basic knowledge on the conditions in fire resistance furnaces according to standard ISO or EN fire curves gave us the insight that, during these tests, the test specimen is exposed to over $100 \mathrm{~kW} / \mathrm{m}^{2}$ radiative heat flux in addition to about $15 \mathrm{~kW} / \mathrm{m}^{2}$ convective heat flux. In our case, the actual façade will be exposed to not more than $41 \mathrm{~kW} / \mathrm{m}^{2}$.

Our goal was to find an economic solution without using fire resistant glazing. The target was set by the local authorities: keep the radiative heat flux inside the building below $10 \mathrm{~kW} / \mathrm{m}^{2}$, preferably even below $3 \mathrm{~kW} / \mathrm{m}^{2}$. This performance level should be present for the expected duration of the fire (30 minutes).

\section{RESEARCH AND DEVELOPMENT}

\section{First fire test}

'Normal' glass has no fire resistance if exposed to the standard fire curve. The behaviour of fire resistant glazing is very well documented, and scattered information is available on the behaviour of non fire resistant glass exposed to internal standard fire, but our company has found little evidence of the behaviour of non-fire resistant glass exposed to an external fire curve. DuPont and Pilkington have 


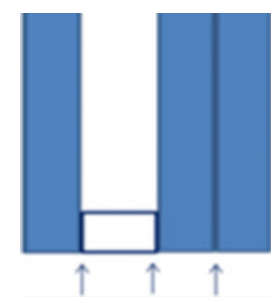

Figure 5. Compositions of IG Units. The arrows show the possible positions of the Low-E coating. The proper composition is not illustrated.

shown, in developing bushfire resistant glass, that a laminated Low-E coated glass could withstand radiation levels of $40 \mathrm{~kW} / \mathrm{m}^{2}$ for a short period of time (2-5 minutes) (2004) [4]. Out of curiosity as to the behaviour of 'normal' insulation glass units exposed to external fire conditions, we organised fire tests at the Efectis Fire Laboratory in Rijswijk (The Netherlands) at the end of 2007.

We tested a simple solar-control IG unit with a laminated inner pane without Low-E coating against the EN 1363-2 fire curve for external fires. The glass configuration withstood exposure for 9 minutes.

\section{Modification of furnace setup}

As mentioned earlier, during a fire test according to the European standards, the test specimen is not only exposed to heat radiation but also to the hot gases of the furnace. The hot gases will transfer heat to the test specimen causing an additional temperature rise in the specimen. Therefore, together with Efectis Test Laboratory, we decided to modify the furnace in such way that it better simulates actual heat exposure for this building.

We designed a wall standing on a distance of $0,25 \mathrm{~m}$ in front of the test furnace in order to limit the exposure to radiation only. The radiation emitted by the furnace was measured in front of the test specimen, on the furnace-side. Test runs without glass showed the heat loss through the 0,25 meter gap between furnace and wall was to big. We did not succeed in reaching the needed radiation level $\left(45 \mathrm{~kW} / \mathrm{m}^{2}\right)$. So we ended up closing of closing of the gap at the top and partly at both sides.

\section{Further testing}

After the modification of the furnace, we tested several different glass configurations, all of them without fire resistant glass pane. IG units composed by a single outer pane and PVB laminated inner pane with Low-E coating were tested in aluminium and steel frames. Both pyrolytic and high performance Low-E coatings on different positions were tested. In some cases, some of the glass panes were composed of heat strengthened glass (Fig. 4).

The results of these tests are remarkable. Basically, the IG units with Low-E coating on the right position were able to withstand heat flux of $41 \mathrm{~kW} / \mathrm{m}^{2}$ for 27 minutes and reduced the radiation level at 1 metre behind the glass to $2 \mathrm{~kW} / \mathrm{m}^{2}$. The configuration with heat strengthened glass panes did not fail for 60 minutes.

Note: these results are only directly applicable to the project 'The Rotterdam' as the critical heat flux level was calculated for local conditions. The furnace was modified for the testing according to the special requirements. The results are not applicable for commercial targets (CE marking).

\section{Testing again to external fire exposure}

Because of the results of the IG unit, where heat strengthened glass is used for some of the panes, we decided to test this composition according to the European standards for external fire exposure. This 


\section{MATEC Web of Conferences}

glass configuration withstood exposure for 40 minutes. The IGU unit has received the classification EW30-ef according to EN 13501-2 and, therefore, it is exploitable under CE marking.

\section{CONCLUSION}

In an attempt to find a cost effective way to protect the project "The Rotterdam" without fire resistant façade construction, and more specifically without fire resistant glazing, our engineers exposed "normal" insulation glass units to external fire conditions. The results show that a smart composition of a laminated inner pane, Low-E coating, and a heat strengthened glass pane at the right positions can achieve the classification of EW30-ef. This insulated glass unit is an economical solution for the façade of projects where external fire exposure poses a risk.

\section{DISCUSSION}

We are confident this economic solution will contribute solving issues with external fires in places where fire protection otherwise would be a major cost issue. This will not be limited to densely populated areas near transport routes of dangerous goods. As we know we did not succeed in a radiation only test we think we will be able to optimize the economics of this solution. In particular the measures to fire proof the window frames could probably be simplified if the only load would be radiation.

For the future we would like to work on the development of a reliable and economic "radiation only" test method. We hope this conference will help us to find out if this is not only our "need" or whether this is also recognised on a European of global level.

\section{References}

[1] Molag, M, Leur, P. van de, Vredeveldt, L., Stax, L., Aspects and backgrounds for a developmentfree zone along the New Waterway and the New Maas related to transport of dangerous goods, TNO Milieu, Energie en Procesinnovatie, TNO-MEP-R 2002/266, July 2002.

[2] Committee for the Prevention of Disasters Voorburg, Methods for the Calculation of Physical Effects: Part 2 CPR 14E, 1997/2005, ISBN 9012084970.

[3] Molag, M, Reinders, J. E. A., Wiersma, T., Safety Evaluation for the High-rise project 'The Rotterdam' on the Wilhelminapier in Rotterdam, TNO, 2 September 2005, no. 35443.

[4] Bushfire Resistant Windows Introduced by Pilkington and DuPont, News Item Building Product News, 02/02/2004. 